\title{
Understanding W Doping in Wurtzite ZnO
}

\author{
Francesc Viñes, ${ }^{1}$ Ana Iglesias-Juez, ${ }^{2}$ Marcos Fernández-García, ${ }^{2}$ and Francesc Illas, ${ }^{1, *}$ \\ ${ }^{1}$ Departament de Ciència de Materials i Química Física \& Institut de Quimica Teòrica i \\ Computacional (IQTCUB), Universitat de Barcelona, c/Martí i Franquès 1,08028 \\ Barcelona, Spain \\ 2. Instituto de Catálisis y Petroleoquímica, CSIC, c/Marie Curie 2, \\ Cantoblanco, 28049 Madrid, Spain.
}

\begin{abstract}
In the context of bandgap engineering of the $\mathrm{ZnO}$ photoactive material for solar harvesting applications via $\mathrm{W}$ doping, a number of a priori discrepant experimental observations in the literature concerning $\mathrm{ZnO} c$ axis expansion/contraction, bandgap red- or blue-shifting, the $\mathrm{Zn}$ substitutional or interstitial nature of $\mathrm{W}$ atoms, or the $\mathrm{W}^{6+}$ charge compensation view with $\mathrm{ZnO}$ native defects are addressed by thorough density functional theory calculations on a series of bulk supercell models encompassing a large range of $\mathrm{W}$ contents. The present results reconcile the at first sight dissimilar observations by showing that interstitial $\mathrm{W}\left(\mathrm{W}_{\mathrm{i}}\right)$ is only energetically preferred over substitutional $\left(\mathrm{W}_{\mathrm{Zn}}\right)$ at large large $\mathrm{W}$ doping concentrations; the $\mathrm{W}_{\mathrm{Zn}} c$ lattice expansion can be compensated by a $\mathrm{W}$ triggered $\mathrm{Zn}$-vacancy $\left(\mathrm{V}_{\mathrm{Zn}}\right) c$ lattice contraction. The presence of $\mathrm{W}_{\mathrm{Zn}}$ energetically fosters nearby $\mathrm{V}_{\mathrm{Zn}}$ defects, and vice versa, up to a double $\mathrm{V}_{\mathrm{Zn}}$ situation. The quantity of mono or divacancies explains the lattice contraction/expansion, and both limiting situations imply gap states which reduce the band gaps, but increase the energy gaps. Based on present results, the $\mathrm{ZnO}$ band gap red-shifting necessary for solar light triggered processes is achievable by $\mathrm{W}$ doping in $\mathrm{Zn}$ rich conditions.
\end{abstract}

\footnotetext{
*corresponding authors: francesc.illas@ub.edu
} 


\section{Introduction}

Because of its appealing high electron mobility and good thermal conductivity, a direct bandgap $(\sim 3.4 \mathrm{eV})$ in the near-visible ultraviolet (UV) region, and a large exciton binding energy ( $\sim 60 \mathrm{meV})$, wurtzite zinc oxide $(\mathrm{ZnO})$ is among the most studied materials in the field of photocatalysis. ${ }^{1-3}$ This material is also at the heart of some technological applications including semiconductors, ${ }^{4}$ field-effect transistors, ${ }^{5}$ photodetectors, ${ }^{6}$ blue- and UV-light emitting and laser diodes, ${ }^{7-9}$ piezoelectric generators, ${ }^{10}$ transparent electrodes, ${ }^{11}$ and solar cells for sunlight harvesting. ${ }^{12-14}$

Concerning sunlight utilization, $\mathrm{W}$ doping has been considered as a promising strategy to improve the $\mathrm{ZnO}$ efficiency, given that $\mathrm{WO}_{3}$ features a smaller band gap in the 2.6-3.0 eV range. ${ }^{15,16}$ In this sense, small quantities of $\mathrm{W}$ embedded in $\mathrm{ZnO}$ have been shown to reduce the band gap towards the visible region, while at the same time helping in decreasing the photoexcited electron/hole exciton recombination rate. ${ }^{17}$ This is clear from experiments evidencing a significant enhanced photocatalytic activity towards methylene blue dye degradation of $\mathrm{W}$-doped $\mathrm{ZnO}$ as compared to pure $\mathrm{ZnO} .{ }^{18}$ Note also that $\mathrm{W}$-doped $\mathrm{ZnO}$ nanocomposites have been also used as heterogeneous nanocatalysts for biscoumarins synthesis in liquid environment. ${ }^{19}$

From the previous discussion it is clear that $\mathrm{W}$ doping of $\mathrm{ZnO}$ is regarded as an strategy to enhance or fine-tune the $\mathrm{ZnO}$ (photo)catalytic activity. However, the geometric and electronic structure atomistic details are far from being understood and not exempt of controversy in the literature. Following evidence from by X-ray diffraction (XRD) experiments on nanosystems, ${ }^{17,20-23}$ many experimental groups report that the preferred $\mathrm{W}$ growing direction is along the $\mathrm{ZnO}(0001)$ basal plane. However, the particular site of $\mathrm{W}$ inside the $\mathrm{ZnO}$ crystalline network is hitherto a matter of discussion. For instance, from the analysis of X-ray photoemission spectroscopy (XPS) data, Can et al. ${ }^{20}$ claim that $\mathrm{W}$ is 
coordinated to $\mathrm{O}$ atoms, corresponding to a replacement of a host $\mathrm{Zn}\left(\mathrm{W}_{\mathrm{Zn}}\right)$ atom. This assignment is in concordance with interpretation of low energy $\mathrm{He}^{+}$ion scattering spectroscopy on $\mathrm{ZnO}$ films reported by Suzuki and coworkers. ${ }^{24}$ However, other authors point that, as there is no significant change of the crystal structure along the $c$ axis when including $\mathrm{W}$, the $\mathrm{W}$ becomes interstitial $\left(\mathrm{W}_{\mathrm{i}}\right),{ }^{22}$ an issue also discussed by Sato et al. ${ }^{17}$ in the view of high-resolution transmission electron microscopy (HR-TEM) measurements. To make it more complex, Ngom and coworkers ${ }^{21}$ argue that the presence of $\mathrm{W}_{\mathrm{Zn}}$ or $\mathrm{W}_{\mathrm{i}}$ depends on the temperature, with $\mathrm{W}_{\mathrm{i}}$ being favoured at low temperatures. However, XRD patterns show no significant change with respect the $\mathrm{W}$ content, a point that contradicts the $\mathrm{W}_{\mathrm{Zn}}$ substitution, as the ionic radius of $\mathrm{W}^{6+}$ in $\mathrm{WO}_{3}(0.42 \AA)$ is smaller ionic than that of $\mathrm{Zn}^{2+}$ in $\mathrm{ZnO}(0.60 \AA),{ }^{25}$ indicating a contraction of the crystal $\mathrm{ZnO}$ structure under $\mathrm{W}_{\mathrm{Zn}}$ doping.

Nevertheless previous studies suggested that $\mathrm{W}_{\mathrm{Zn}}$ is accompanied by the formation of two $\mathrm{Zn}$ vacancies formation $\left(\mathrm{V}_{\mathrm{Zn}}\right),{ }^{26}$ energetically preferred over two interstitial oxygens $\left(\mathrm{O}_{\mathrm{i}}\right){ }^{27}$ The appearance of $\mathrm{V}_{\mathrm{Zn}}$ would counteract the four extra electrons when having $\mathrm{W}_{\mathrm{Zn}}$ and the concomitant contraction expected from the smaller ionic radius of the formally $\mathrm{W}^{6+}$ cation would be counteracted by a lattice expansion due to the presence of $\mathrm{V}_{\mathrm{Zn}}$. This charge compensation mechanism seems to be a current paradigm, ${ }^{24}$ which also serves to explain the reduced charge carrier efficiency $\mathrm{W}$-doped $\mathrm{ZnO}$, quantified to be below 0.15 e per $\mathrm{W}$ atom. ${ }^{26}$

However, there is no consensus as other authors highlight the enhanced free-carrier density of $\mathrm{W}$-doped $\mathrm{ZnO}$ films at low pressures and link the free-carrier enhancement to a transmittance reduction. ${ }^{28}$ Yet, other works reveal transmittance lowering with absorption edge changes. ${ }^{26}$ Indeed, the effect of $\mathrm{W}$ doping on the band gap is a central issue in the literature where conflicting blue shifts ${ }^{17,28}$-increased band gap, $\mathrm{E}_{\mathrm{g}}$ - , red shifts, ${ }^{18,29}$ and no shifts $^{21,22,26}$ are reported. A quite extensive theoretical study predicts a $E_{\mathrm{g}}$ blue shift ${ }^{30}$ although calculations are carried out with the Local Density Approximation (LDA) of Density 
Functional Theory (DFT) which, due to its inherent self-interaction error, needs to be taken with caution. In fact, a more recent work using a more accurate GGA+U type density functional reports a red shift on the band gap induced by $\mathrm{W}$ doping and also a switch in the variation of the volume with respect to $\mathrm{W}$ concentration. ${ }^{31}$ Last but not least, doping $\mathrm{ZnO}$ with transition metals is known to confer magnetic properties, ${ }^{32}$ although specifically with W it seems as such occurs only at very low temperatures below $10 \mathrm{~K},{ }^{20}$ and may be quenched at high doping concentration. ${ }^{32}$

In order to clarify these issues and provide a background to the experimental interpretations, we fully address here $\mathrm{W}$-doping in wurtzite bulk $\mathrm{ZnO}$ by means of DFT calculations, including aspects of doping agent allocation $\left(\mathrm{W}_{\mathrm{Zn}}\right.$ versus $\left.\mathrm{W}_{\mathrm{i}}\right)$, structural changes (cell expansion/contraction), fostering of other native defects, such as $\mathrm{V}_{\mathrm{Zn}}$, plus assessing the energetic costs and electronic structure changes as a matter of $\mathrm{W}$ dopant concentration, with the ultimate goal of rationalizing past experiences, and to pave the way for future work on Wdoped $\mathrm{ZnO}$ in photocatalysis.

\section{Computational Details and Material Models}

Calculations have been carried out in the fundamental DFT framework and within the generalized gradient approximation (GGA) for the exchange-correlation potential, although one has to keep in mind that larger dynamical aspects could affect the $\mathrm{W}$-doped $\mathrm{ZnO}$ average properties, yet should be treated at a larger scale of simulation, nowadays unachievable. ${ }^{33}$ Specifically on DFT, the Perdew-Burke-Ernzerhof (PBE) form of GGA exchange-correlation functional has been chosen. ${ }^{34}$ This functional is known to duly describe the structural and energy bond features of $\mathrm{ZnO}$ nanosystems. ${ }^{35}$ Nevetheless, LDA, and GGA functionals like PBE are known to underestimate the band gap of semiconducting oxides ${ }^{36}$ and hybrid functionals are recommended to properly describe the magnitude of the band gap or of localized gap states, being PBE0 a suited option for $\mathrm{ZnO}$ and $\mathrm{ZnO}$-based systems, with a bulk 
$\mathrm{ZnO}$ band gap estimation of $3.18 \mathrm{eV} \cdot{ }^{37}$ Alternatively, one can use many body perturbation theory based calculations as in the $G W$ scheme which deliver a bulk $\mathrm{ZnO}$ value for the band gap of $3.08 \mathrm{eV},{ }^{38}$ still much improved compared to a PBE value of $0.83 \mathrm{eV} .^{43}$ However, a direct linear proportionality between $G W$ and PBE0 versus PBE calculated band gap values has been reported for $\mathrm{ZnO},{ }^{37,38}$ which has been quite recently generalized to a large set of semiconductors where the agreement between $G W$ calculated values and experimental data is also highlighted. ${ }^{39}$ Appling such a $G W$ scaling to the present PBE calculated value for bulk $\mathrm{ZnO}$ provides a band gap of $3.32 \mathrm{eV}$, remarkably close to the experimental one. This useful linear scaling relationship allows a meaningful discussion of computationally less expensive PBE-based band gaps, which is to be accompanied at the grounded PBE0 or $G W$ levels. Nevertheless, when necessary, $\mathrm{PBE}+\mathrm{U}$ simulations ${ }^{40}$ have been carried out in a single-point fashion, imposing a standard $\mathrm{U}$ value of 5 for $\mathrm{Zn} 3 d$ and W $5 d$ electrons.

The DFT based calculations have been carried out using the Vienna ab initio simulation package VASP, ${ }^{41}$ and employing a plane-wave basis set to expand the valence electron density. A kinetic energy cutoff of $415 \mathrm{eV}$ has been used to select the plane wave basis set which, according to previous studies with representative test cases with increased cutoff energies, ${ }^{42,43}$ provides converged energy results with variations below $1 \cdot 10^{-4} \mathrm{eV}$. The effect of the core electrons on the valence electron density is described by the projector augmented wave (PAW) method. ${ }^{44}$

Different periodic supercells have been used as described in more detail below. In all cases, all atomic and unit cell degrees of freedom were fully allowed to relax during the energy minimization procedure. Structural optimizations were considered converged when cell internal pressure was nominally below $0.01 \mathrm{GPa}$ and forces acting on atoms were below $0.01 \mathrm{eV} \AA^{-1}$. All calculations were carried out taking spin-polarization into account despite, in most cases, the final total magnetic moment is zero. To enhance convergence of energy with 
respect to electron density variations a smearing technique was employed with a tetrahedron method with Blöchl corrections with an energy window of $0.2 \mathrm{eV}$. Nevertheless, final energies are always extrapolated to $0 \mathrm{~K}$.

Different doping situations including or not point defects are considered thus allowing the simulation of different doping concentrations. To this end, a series of different bulk supercells have been designed starting from the wurtzite $\mathrm{ZnO}$ primitive unit cell, see Table 1. The use different unit cells implies also a different sampling of k-points to carry out the necessary numerical integration in the reciprocal space. Hence, Monkhorst-Pack ${ }^{45}$ grids different dimensions adapted to the different supercells have been used as reported in Table 1. Test calculations carried out for the $(1 \times 1 \times 1)$ primitive unit cell using denser k-points grids yielded energy variations below $1 \cdot 10^{-4} \mathrm{eV}$. Table 1 also reports the atomic $\%$ of doping or defect concentration, defined as having only one single point defect or doping $\mathrm{W}$ atom introduced in the employed periodic cell, and considering that the concentration percent (at.\%) refers to the total amount of $\mathrm{W}$ atoms or defects in the defect- or doping-free unit cell relative to the stoichiometric case. Since $a$ and $b$ lattice parameters in wurtzite $\mathrm{ZnO}$ are identical while $c$ is different, needs to adverted that diverse supercells such as $(1 \times 1 \times 2)$ and $(2 \times 1 \times 1)$ contain the same number of atoms but represent different atomic arrangements. Hence, all different possible different permutations have been considered up to the $(2 \times 2 \times 2)$ supercell. Note in passing by that in very small supercells, the introduced defects can interact with the replicated ones under periodic boundary conditions, and so, results on such very small supercells are considered fringe situations to capture trends, where the $(2 \times 2 \times 2)$ supercell upwards provide more realistic descriptions of the W-doping and other defects.

The defect or doping formation energy, $E_{f}$, is defined considering isolated atoms in vacuum as reference values, and, therefore, deliberately assuming poor conditions for any component in such ternary phase diagram. Note, that this treatment differs with previous 
considerations on native point defects on $\mathrm{ZnO}$ where the chemical potentials of $\mathrm{O}$ and $\mathrm{Zn}$ are linked in the upper bound limits to $\mathrm{O}_{2}$ and bulk $\mathrm{Zn}$, and in the lower bound limit to the formation of $\mathrm{ZnO}$. However, the involvement of $\mathrm{W}$ implies other upper lower bound limits such as bulk $\mathrm{W}$, and lower bound limits such as $\mathrm{WO}_{3}$ and $\mathrm{WZn}$ alloy that difficult the analysis. Thus, we deliberately impose poor conditions on all the elements, as the enrichment of any will difficult (favour) its insertion (release) from the $\mathrm{ZnO}$ matrix. The isolated atoms are calculated by placing them in an asymmetric periodic cell of $9 \times 10 \times 11 \AA$ dimensions to prompt correct orbital energy occupations and taking into account the $\Gamma$-point only. Thus, $E_{f}$ is obtained as

$$
E_{f}=E_{D / Z n O}+E_{A}-E_{Z n O}-E_{D}
$$

where $E_{Z n O}$ is the total energy of the defect- or dopant-free $\mathrm{ZnO}$ bulk cell, $E_{D / Z n O}$ the total energy of the $\mathrm{ZnO}$ cell containing the native defect or the doping atom, $E_{D}$ is the total energy of the isolated doping atom, here $\mathrm{W}$, when present in $E_{D / Z n O}$, and $E_{A}$ the total energy of the removed $\mathrm{ZnO}$ atom when considering $\mathrm{Zn}$ or $\mathrm{O}$ vacancies, $\mathrm{V}_{\mathrm{Zn}}$ and $\mathrm{V}_{\mathrm{O}}$, respectively. Aside from considering $\mathrm{V}_{\mathrm{Zn}}$ and $\mathrm{V}_{\mathrm{O}}$, the most likely defects in $\mathrm{O}$ - and $\mathrm{Zn}$-rich conditions, respectively, according to previous LDA calculations, we consider here interstitial $\mathrm{W}\left(\mathrm{W}_{\mathrm{i}}\right)$, and $\mathrm{W}$ substituting lattice $\mathrm{Zn}\left(\mathrm{W}_{\mathrm{Zn}}\right)$ and $\mathrm{O}$ atoms $\left(\mathrm{W}_{\mathrm{O}}\right)$. Notice that previous works contemplated interstitial Oxygen $\left(\mathrm{O}_{\mathrm{i}}\right)$ as a possible counter charge mechanism to $\mathrm{W}_{\mathrm{Zn}}{ }^{26}$ although it was found that $\mathrm{V}_{\mathrm{Zn}}$ is energetically more favourable than $\mathrm{O}_{\mathrm{i}},{ }^{27}$ and, therefore, $\mathrm{O}_{\mathrm{i}}$ has not been further considered. Further, note that even though the formation energetics is treated at PBE level, former studies comparing $\mathrm{V}_{\mathrm{O}}$ formation in O-poor environment at different concentrations revealed mean unsigned variations of $0.29 \mathrm{eV}$ when carried out PBE or employing the PBE0 hybrid functional. ${ }^{37}$ Moreover, the formation energies of a diversity of native defects as computed at LDA and LDA+U revealed mean unsigned variations of 0.45 $\mathrm{eV} .{ }^{46}$ As it will shown below, the differences in formation energies are much larger than such 
method-based deviations, and so, such an effect is to be disregarded in the oncoming discussion. In any case, when formation energies differ by such amounts, they are considered competitive.

\section{Results and Discussion}

\subsection{Single Defects and Dopants}

We first discuss the formation energies of native defects and $\mathrm{W}$-doping situations calculated as in Eq. 1 and summarized on Table 2. The calculated values for $\mathrm{V}_{\mathrm{Zn}}$ and $\mathrm{V}_{\mathrm{O}}$ are in line with previously reported LDA results of 6.60 and $6.47 \mathrm{eV}$ for $\mathrm{V}_{\mathrm{Zn}}$ and $\mathrm{V}_{\mathrm{O}}$ in $\mathrm{Zn}$-poor and O-poor

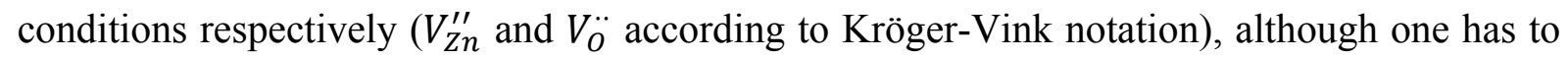
keep in mind the interaction overestimation provided by LDA in such a comparision. ${ }^{27}$ However, it is more interesting to note that, under the same conditions, substitutional W $\left(\mathrm{W}_{\mathrm{Zn}}\right)$ and interstitial $\mathrm{W}\left(\mathrm{W}_{\mathrm{i}}\right)$ feature highly negative formation energies, whereas normally $\mathrm{W}_{\mathrm{O}}$ feature positive values. This highlights the swift blending of $\mathrm{W}$ within the $\mathrm{ZnO}$ crystallographic network, and, at the same time, the possible competition between $\mathrm{W}_{\mathrm{Zn}}$ and $\mathrm{W}_{\mathrm{i}}$, while discarding completely $\mathrm{W}_{\mathrm{O}}$ as a possible doping situation.

Figure 1 reports the $E_{f}$ trends with respect to the defect or doping concentration and shows that in the case of native defects, the corresponding values do not largely vary with the defect content, with fluctuations of at most $1 \mathrm{eV}$. This behaviour is consistent with a rather modest structural reorganization upon vacancy formation, at least within the used DFT method. However, in the case of the $\mathrm{W}$ doping situations the formation energy is quite more dependent on the $\mathrm{W}$ content. Typically, $\mathrm{W}$ doping is favourable and its stability increases by more than $2.3 \mathrm{eV}$ when going from 12.5 to 50 at. \%, a feature consistently found for all the three situations explored. These results clearly reveals that high $\mathrm{W}$ contents are achievable, a key matter when aiming at tuning the properties of $\mathrm{ZnO}$ which is also consistent with experimental finding that doping with $\mathrm{W}$ achieved contents up to 15 at. $\%{ }^{26}$ Nevertheless it is 
also important to realize that the behaviour of the three different doping situations changes below 12.5 at. \%; $\mathrm{W}_{\mathrm{O}}$ becomes destabilized by more than $2.7 \mathrm{eV}$, whereas this is roughly 1.7 $\mathrm{eV}$ for $\mathrm{W}_{\mathrm{i}}$. Interestingly, the trend gets reverted in the case of $\mathrm{W}_{\mathrm{Zn}}$, becoming highly stable at very low concentrations of $\sim 1.85$ at. $\%$. This seems to explain the different studies pointing to the presence of $\mathrm{W}_{\mathrm{i}},{ }^{17,22}$ or $\mathrm{W}_{\mathrm{Zn}},{ }^{20,24}$ or even one or another depending on the temperature. ${ }^{21}$

Concerning lattice expansion/contraction triggered by W-doping, Figure 2 shows the calculated lattice variation along the $c$ axis $(\Delta c)$ given in percentile with respect to pristine, defect free, wurtzite $\mathrm{ZnO}$, with the corresponding numerical values reported in Table 3 . Again, the trends corresponding to either $\mathrm{Zn}$ or $\mathrm{O}$ vacancies are similar, yielding a lattice contraction, which implies a bond strengthening within $\mathrm{ZnO}$ in response to undercoordination of some atoms in the lattice. The largest changes occur, not surprisingly, at high defect concentrations whereas at low concentrations the changes are almost negligible. On the contrary, W doping tends to imply a lattice expansion, whatever the doping situation is considered, specially at medium and high W doping concentration.

Experiments show a $c$-axis enlargement increasing with $\mathrm{W}$ content from 1 up to 14 at. $\%$ of $\mathrm{W} .{ }^{26}$ Precisely, Adachi et al. ${ }^{26}$ argued that the aforementioned reduced ionic radius of $\mathrm{W}^{6+}$ compared to $\mathrm{Zn}^{2+}$ would allow for $\mathrm{W}_{\mathrm{Zn}}$ situations, and that this would then decrease the $c$ axis. However, the present results suggest that this hypothesis is not always supported since even if the presence of $\mathrm{W}$ doping tends to follow this trend, it is here found that the $c$ axis contracts by $-0.59 \%$ at $\mathrm{W}_{\mathrm{Zn}}$ content of 1.85 at. $\%$, although it expands by $0.27 \%$ when $\mathrm{W}_{\mathrm{Zn}}$ content becomes 6.25 at. \%. Also, these authors argued that the presence of $\mathrm{V}_{\mathrm{Zn}}$ would lead to an increase of the lattice along the $c$ direction, which is consistent with present results predicting an expansion of 1.57 and $1.80 \%$ for realistic defect contents of 1.85 and 6.25 at. $\%$, respectively. Therefore, one can safely conclude that $i$ ) $\mathrm{W}$ doping at any of the explored 
sites tends to expand the $c$ axis, $i$ ) the effect is milder for $\mathrm{W}_{\mathrm{Zn}}$ compared to $\mathrm{W}_{\mathrm{i}}$, and $\left.i i i\right)$ at very low $\mathrm{W}$ contents the observed expansion could be attributed to the presence of $\mathrm{V}_{\mathrm{Zn}}$.

Last, we discuss the magnetic properties of defective $\left(\mathrm{V}_{\mathrm{O}}\right.$ or $\left.\mathrm{V}_{\mathrm{Zn}}\right)$ and $\mathrm{W}$-doped $\mathrm{ZnO}$ by inspecting the number of unpaired electrons in the corresponding spin polarized solutions. The cell total magnetic moment $\mu$ is shown in Table 4, and trends plot in Figure 3. The most prominent features are that the presence of $\mathrm{V}_{\mathrm{O}}$ does not bestow any magnetic moment at all at any of the explored concentrations, plus the existence of $\mathrm{W}_{\mathrm{O}}$ barely does, but at very low concentrations, only. However, the most likely $\mathrm{W}_{\mathrm{Zn}}, \mathrm{V}_{\mathrm{Zn}}$ and $\mathrm{W}_{\mathrm{i}}$ situations introduce a magnetic moment of $\sim 2 \mu_{\mathrm{B}}$, yet this occurs essentially at low dopant concentrations. In fact, upon increasing dopant concentration the interaction between $\mathrm{W}$ centers lead to a final diamagnetic solution. Note that the abrupt decays occur first for $\mathrm{W}_{\mathrm{i}}$, later $\mathrm{W}_{\mathrm{Zn}}$, and finally $\mathrm{V}_{\mathrm{Zn}}$, and so, the doped material would have a magnetic response at low concentrations only. This goes along with previous positive magnetoresistivity and polarized spin currents in W doped $\mathrm{ZnO}$ films with 1-2 at. \% W content. ${ }^{20}$ A special case is the limit situation of 50 at. \% content of $\mathrm{V}_{\mathrm{Zn}}$, where a significantly high magnetic moment of $1.88 \mu_{\mathrm{B}}$ is found. Notice that this is a highly fringe situation, and, therefore, the electronic coupling can well be regarded as different from the $\mathrm{ZnO}$ matrix, this being the source of such outlying situation.

As far as the bandgap $E_{g}$ is concerned, the single incorporation of vacancies or W implies an electron carrier increment, either holes (in $\mathrm{V}_{\mathrm{O}}$ ) or electrons (in $\mathrm{V}_{\mathrm{Zn}}, \mathrm{W}_{\mathrm{Zn}}, \mathrm{W}_{\mathrm{i}}$, and $\mathrm{W}_{\mathrm{O}}$ ), and no bandgap can be assigned to such systems, as they behave as metallic, unless combinations of defects are introduced, see below. For the most likely W-doping situations, these are, $\mathrm{W}_{\mathrm{i}}$ and $\mathrm{W}_{\mathrm{Zn}}$, the Bader ${ }^{47}$ charges analysis on the $(2 \times 2 \times 2)$ supercell reveal $\mathrm{W}$ atoms getting oxidized by 2.12 and $2.89 e$, respectively, and so, transferring these electrons to the host $\mathrm{ZnO}$. Indeed, the electron carrier increment in W-doping situations is alleged to be responsible of an enhanced free-carrier density. ${ }^{28}$ However, the sole inclusion of W would 
imply that the conduction band becomes occupied, converting semiconductor $\mathrm{ZnO}$ in effectively a metal, as prognosticated by DFT LDA calculations. ${ }^{30}$ Likewise, one must advert of the well-known trend of LDA calculations to significantly underestimate the band gap of oxides. ${ }^{36,48}$ On the other hand, some authors point that the charge introduced by adding $\mathrm{W}^{6+}$ cations, as detected by XPS, ${ }^{23}$ is counteracted by the formation of two $\mathrm{Zn}^{2+}$ vacancies per $\mathrm{W}^{6+}$ ion. ${ }^{24}$ This coexistence of $\mathrm{W}_{\mathrm{Zn}}$ with $2 \mathrm{~V}_{\mathrm{Zn}}$ results in a doping efficiency below $0.15 \mathrm{e} / \mathrm{W} .^{26}$ Note in passing by that such oxidation states are idealizations of a charge accumulation/depletion, rather than a direct measurement of an observable linked to ascribed number of electrons. ${ }^{49}$ The coexistence of $\mathrm{W}_{\mathrm{Zn}}$ and $\mathrm{V}_{\mathrm{Zn}}$ entities is treated next.

\subsection{Effect of simultaneous $W$-doping in the presence of $V_{Z n}$}

Here, we focus the study to very small quantities of $\mathrm{W}$, as they are the most commonly encountered situation in experiments..$^{20,22,23,26,29,50}$ To this end, only $(2 \times 2 \times 2)$ and $(3 \times 3 \times 3)$ supercells are further considered. Note also that at these low $\mathrm{W}$ doping concentration, $\mathrm{W}_{\mathrm{Zn}}$ is energetically preferred over $\mathrm{W}_{\mathrm{i}}$, see Figure 1 . First, we consider the coexistence of a $\mathrm{W}_{\mathrm{Zn}}$ and a single $V_{Z n}$ vacancy by evaluating whether $V_{Z n}$ is energetically more stable in the same basal (0001) plane where $\mathrm{W}_{\mathrm{Zn}}$ is located, or perpendicular to it, yet always considering a nearby situation between both entities. The structural optimization on the $(2 \times 2 \times 2)$ supercell shows that a (0001) planar vicinal coexistence is clearly energetically more favourable than the perpendicular one by $1.39 \mathrm{eV}$, in full consistency with the XRD data in nanosystems. ${ }^{17,20-23}$ Notice that simultaneous formation of $\mathrm{V}_{\mathrm{Zn}}$ point defect and the $\mathrm{W}_{\mathrm{Zn}}$ substitution $\left(\mathrm{W}_{\mathrm{Zn}}+\mathrm{V}_{\mathrm{Zn}}\right)$ is energetically stable by $-3.23 \mathrm{eV}$. On the $(3 \times 3 \times 3)$ supercell nearby $\mathrm{W}_{\mathrm{Zn}}+\mathrm{V}_{\mathrm{Zn}}$ formation on the basal (0001) plane is preferred over a more distant defect location by $\sim 0.7 \mathrm{eV}$, plus the simultaneous $\mathrm{W}_{\mathrm{Zn}}+\mathrm{V}_{\mathrm{Zn}}$ formation is even more energetically preferred by $-4.90 \mathrm{eV}$. Thus, $\mathrm{V}_{\mathrm{Zn}}$ point defects favour the nearby $\mathrm{Zn}$ substitution by $\mathrm{W}$, and, concomitantly, the $\mathrm{W}_{\mathrm{Zn}}$ doping 
situation fosters the Zn vacancy formation nearby, and so, such defects are to be located close to each other.

The above-commented energetic stability is further investigated on the $(2 \times 2 \times 2)$ supercell, the most prominent feature being that, according to present results, $\mathrm{W}_{\mathrm{Zn}}$ energetically favours the presence of $\mathrm{V}_{\mathrm{Zn}}$. The creation of $\mathrm{W}_{\mathrm{Zn}}$ in a 6.25 at. \% concentration has an energetic gain of $-3.66 \mathrm{eV}$, see Table 2, even considering that $\mathrm{Zn}$ is removed from the system. However, the cost of adding a nearby $\mathrm{V}_{\mathrm{Zn}}$ in the same basal plane of $\mathrm{W}_{\mathrm{Zn}}$ is only of $0.46 \mathrm{eV}$, a highly reduced cost compared to that corresponding to the formation of an equivalent $\mathrm{V}_{\mathrm{Zn}}$ cost on pristine $\mathrm{ZnO}$ estimated as $6.40 \mathrm{eV}$, see Table 2. Clearly, the charge compensation mechanism is efficient and largely favours $\mathrm{W}_{\mathrm{Zn}}+\mathrm{V}_{\mathrm{Zn}}$ formation $^{24}$ and, at the same time, indicates that the enhancement of free-carrier density by $\mathrm{W}$ doping hypothesis ${ }^{28}$ does not hold. Along this line, the $\mathrm{W}_{\mathrm{Zn}}$ gets further oxidized to $+3.32 e$ in the presence of $\mathrm{V}_{\mathrm{Zn}}$ compared to the above commented value of $+2.89 e$ in the absence of $\mathrm{V}_{\mathrm{Zn}}$ according to Bader analysis of the electron density, thus confirming the charge compensation mechanism.

Finally, the coexistence of vicinal $\mathrm{W}_{\mathrm{Zn}}$ and $\mathrm{V}_{\mathrm{Zn}}$ leads to a closed shell type solution (no magnetic moment) even though separately both defects would present a magnetic moment (Table 4). This result indicates that $\mathrm{W}_{\mathrm{Zn}}$ and $\mathrm{V}_{\mathrm{Zn}}$ interact to each other by coupling their unpaired electrons. Furthermore, the $\Delta c$ of isolated $\mathrm{W}_{\mathrm{Zn}}$ and $\mathrm{V}_{\mathrm{Zn}}$ would be of 0.27 and -0.11 $\%$ whereas when coupled together the total $\Delta c$ becomes $-0.32 \%$. This reconciles the alleged $c$ lattice reduction when introducing $\mathrm{W}_{\mathrm{Zn}}$ with the forecasted $c$ lattice expansion predicted by the present DFT based calculations. Apparently, the interaction between $\mathrm{W}_{\mathrm{Zn}}$ and $\mathrm{V}_{\mathrm{Zn}}$ is the responsible for the $\mathrm{ZnO}$ lattice contraction along the $c$ direction, actually well beyond the mere existence of solely $\mathrm{W}_{\mathrm{Zn}}$ or $\mathrm{V}_{\mathrm{Zn}}$.

Last, analysis of the Density Of States (DOS) for $\mathrm{W}_{\mathrm{Zn}}+\mathrm{V}_{\mathrm{Zn}}$ in a situation represented by $(2 \times 2 \times 2)$ supercell (Figure 4$)$ reveals a finite band gap $\left(E_{g}\right)$ of $0.26 \mathrm{eV}$, a value which is 
likely to be underestimated ${ }^{36,48}$ although with trends likely to be accurate enough. ${ }^{39}$ Note, however, that this band gap arises from midgap states arising from a mixture of $\mathrm{W}, \mathrm{Zn}$, and $\mathrm{O}$ orbital components. Indeed, the energy gap between the formerly $\mathrm{ZnO}$ valence and conduction bands - essentially O $2 p$ and $\mathrm{Zn} 4 s$ dominating states - predicted from DFT based calculations using the same PBE functional becomes $1.75 \mathrm{eV}$, significantly larger than the $0.83 \mathrm{eV}$ value for pristine $\mathrm{ZnO}$ obtained with the same computational setup. Consequently, the presence of $\mathrm{W}_{\mathrm{Zn}}+\mathrm{V}_{\mathrm{Zn}}$ leads to a double effect, on the one hand a band gap reduction due to the presence of the $n$-doping $\mathrm{W}$ states and, on the other hand, an increase in the energy gap between the original valence and conduction band. As a result, W-doping by $\mathrm{W}_{\mathrm{Zn}}$ entities involving $\mathrm{V}_{\mathrm{Zn}}$ defects as well, would decrease the band gap towards the visible region, thus providing explanation to experiments where such a red shifting was observed. ${ }^{17,22,29}$ It is worth pointing out that the present results are at variance of previous reports from LDA calculations predicting an increase of optical gap with W content. However, one must remind that only $\mathrm{W}$-doping (no $\mathrm{V}_{\mathrm{Zn}}$ ) was taken into accoung, thus dealing in practice with metal $\mathrm{W}-\mathrm{ZnO}$ solutions. ${ }^{30}$ Note also that some previous experiments did not report change of band gap upon $\mathrm{W}$ doping ${ }^{18}$ even though considering coexistence of $\mathrm{W}_{\mathrm{Zn}}$ with $\mathrm{V}_{\mathrm{Zn} .}{ }^{26}$ However, a much lower content of $\mathrm{W}$, circa 4 at. \%, was considered there which may have lead to not intense enough peaks due to the midgap states introduced by W doping. Interestingly, the increased energy gap between the levels corresponding to pristine valence and conduction triggered by $\mathrm{W}$ doping (Figure 4) could well explain other experimental observations reporting a blue shift of the band gap ${ }^{17,28}$ in situations with very small $\mathrm{W}$ content so as to overlook the middle gap states.

Another point raised is that the $\mathrm{W}^{6+}$ cations charge should be counteracted with $2 \mathrm{Zn}^{2+}$ vacancies per $\mathrm{W}$ atom. ${ }^{26}$ To investigate this possibility several mutual positions were considered within the $(2 \times 2 \times 2)$ supercell for $2 \mathrm{~V}_{\mathrm{Zn}}$ near the $\mathrm{W}_{\mathrm{Zn}}$ site being again the basal 
(0001) in-plane situation the preferred one. There, the $\mathrm{W}_{\mathrm{Zn}}+2 \mathrm{~V}_{\mathrm{Zn}}$ entity has a formation energy cost of $-1.44 \mathrm{eV}$ which indicates that it is physically feasible and the electronic ground state has zero magnetic moment, where Bader analysis points for an even further oxidation of $\mathrm{W}$ to +4.27 e. However, one must point out that the formation of a second $\mathrm{V}_{\mathrm{Zn}}$ from the $\mathrm{W}_{\mathrm{Zn}}+\mathrm{V}_{\mathrm{Zn}}$ situation would be energetically uphill by $1.51 \mathrm{eV}$. The presence of the $\mathrm{W}_{\mathrm{Zn}}+2 \mathrm{~V}_{\mathrm{Zn}}$ motif leads to an increase of $\Delta c$ of $1.50 \%$, although locally the $\mathrm{W}$ nearby $\mathrm{O}$ atoms approach to the $\mathrm{W}$ atom in a distorted tetrahedron environment, thus untying the remaining $\mathrm{ZnO}$ network, see Figure 5. In the $\mathrm{W}_{\mathrm{Zn}}+2 \mathrm{~V}_{\mathrm{Zn}}$ situation, the band gap increases to $0.52 \mathrm{eV}, 0.26 \mathrm{eV}$ larger than the one corresponding to the $\mathrm{W}_{\mathrm{Zn}}+\mathrm{V}_{\mathrm{Zn}}$ case, but still $0.31 \mathrm{eV}$ smaller than that of pure $\mathrm{ZnO}$. However, as observed in Figure 4 , clustering of $\mathrm{W}_{\mathrm{Zn}}$ with $2 \mathrm{~V}_{\mathrm{Zn}}$ implies an electronic structure rearrangement, with localized yet occupied energy gap states. Here, the energy difference for $\mathrm{ZnO}$ only related states (valence and conduction $\mathrm{ZnO}$ like bands) of $1.19 \mathrm{eV}$ which again can well explain some past blue shifting observations ${ }^{17,28}$ provided doping concentration is small enough to lead to measurable intensity for the defect induced states, yet the gap considering gap states get reduced to $0.52 \mathrm{eV}$. Actually, the fringe situations with $\mathrm{W}_{\mathrm{Zn}}$ coupled to one to two $\mathrm{V}_{\mathrm{Zn}}$ can change the structure of the overall Wdoped system from featuring $c$ contraction of $-0.32 \%$ to $1.5 \%$ expansion. In addition, assuming that, in spite of systematic underestimation of the band gap, the PBE trends can be trusted, yet underestimated, one would predict that $\mathrm{W}$ doping can modulate the band gap by shifts of up to $\sim 1.49 \mathrm{eV}$, i.e. from 0.26 to $1.75 \mathrm{eV}$, or more.

An open question in this matter is whether such energy or band gaps red/blue shifts are actually well represented by the PBE functional. Notice that $G W$ direct proportionality to PBE estimates support the present trends, ${ }^{38}$ yet its calculation remains computationally prohibitive by using a plane-wave basis set on such large supercells. However, to further support the previous statements the $\mathrm{PBE}+\mathrm{U}$ DOS are shown in Figure 6, revealing essentially the same 
trends as for PBE values found in Figure 4. Notice that at this $\mathrm{PBE}+\mathrm{U}$ level, the pure $\mathrm{ZnO}$ bandgap is estimated to be $1.23 \mathrm{eV}$. Thus, the inclusion of a $\mathrm{W}_{\mathrm{Zn}}$ with one or two neighbouring $V_{Z n}$ implies the emergence of gap states, with $\mathrm{W}$ character in the $\mathrm{W}_{\mathrm{Zn}}+\mathrm{V}_{\mathrm{Zn}}$ case, and without in the $\mathrm{W}_{\mathrm{Zn}}+2 \cdot \mathrm{V}_{\mathrm{Zn}}$ one. The bandgap is thus reduced in both situations to $\sim 0.6 \mathrm{eV}$, thus, red shifted from the bulk pure $\mathrm{ZnO}$ value. However, the energy gap in between the $\mathrm{ZnO}$ crystal valence and conduction bands increase to in between 1.74 to $2.10 \mathrm{eV}$. Thus, the $\mathrm{PBE}$ and $\mathrm{PBE}+\mathrm{U}$ red and blue shifts are consistent, and actually the minor effect of the Hubbard $+\mathrm{U}$ correction is to place some states in the gap for the $\mathrm{W}_{\mathrm{Zn}}+\mathrm{V}_{\mathrm{Zn}}$ situation that were overlapping with the conduction band in the PBE estimates.

The present simulations thus strongly suggest that subtle changes in the coexistence of $\mathrm{W}_{\mathrm{Zn}}$ with different quantities of $\mathrm{V}_{\mathrm{Zn}}$ may serve as a mechanism to tune up or down the materials band gap, and by that to offer a way to reconcile the dissimilar experimental observations. According to present studies, the sought red shift of the $\mathrm{ZnO}$ band gap by $\mathrm{W}$ doping seems to be reachable by including a meagre concentration of $\mathrm{V}_{\mathrm{Zn}}$, achievable in $\mathrm{Zn}$ rich conditions.

\section{Conclusions}

In the context of band gap engineering of $\mathrm{ZnO}$ photoactive material for solar harvesting applications, $\mathrm{W}$ doping is regarded as a promising strategy to tune the $\mathrm{ZnO}$ efficiency, even in photocatalytic applications. Although aspects such as a high $\mathrm{W}$ achievable content or the $\mathrm{W}$ placement along (0001) $\mathrm{ZnO}$ basal planes are out debate, there are a number of a priori discrepant observations in the literature concerning the $\mathrm{ZnO} c$ axis expansion/contraction by W-doping, and the red- or blue-shifting (even no-shifting) of the $\mathrm{ZnO}$ bandgap in the same terms of variant $\mathrm{W}$ doping concentrations, as well as the $\mathrm{Zn}$ substitutional or interstitial nature of $\mathrm{W}$ atoms, normally argued based on a $\mathrm{W}^{6+}$ charge compensation view with $\mathrm{ZnO}$ native defects. 
Here, by thorough DFT based calculations on a number of bulk supercell models encompassing a large range of $\mathrm{W}$ contents, we reconcile such disagreements by providing compelling evidence that i) $\mathrm{W}_{\mathrm{i}}$ is energetically preferred to $\mathrm{W}_{\mathrm{Zn}}$ for large $\mathrm{W}$ doping concentrations, but the opposite applies at low W contents, ii) the lattice expansion along the $c$ axis can be compensated by a contraction in the same direction induced by the presence of $\mathrm{V}_{\mathrm{Zn}}$, and iii) $\mathrm{W}_{\mathrm{Zn}}$ energetically fosters formation of nearby $\mathrm{V}_{\mathrm{Zn}}$ in the (0001) basal plane, so as to provide charge compensation by 2 vicinal $\mathrm{V}_{\mathrm{Zn}}$ in the same plane.

The present results for combined presence of $\mathrm{W}_{\mathrm{Zn}}$ and $\mathrm{V}_{\mathrm{Zn}}$ shows a band gap red shift due to the appearance of W-related mid-gap states, but also opens the gap between the nearly O $2 p$ and $\mathrm{Zn} 4 s$ states and leads to an overall contraction along the $c$ axis. A similar situation is predicted for $\mathrm{W}_{\mathrm{Zn}}+2 \mathrm{~V}_{\mathrm{Zn}}$ situation yet with a smaller band gap red shift and a smaller widening of the gap between $\mathrm{O} 2 p$ and $\mathrm{Zn} 4 s$ states and a small $c$ expansion. Thus, the subtle interplay between $\mathrm{W}_{\mathrm{Zn}}+\mathrm{V}_{\mathrm{Zn}}$ and $\mathrm{W}_{\mathrm{Zn}}+2 \mathrm{~V}_{\mathrm{Zn}}$ situations, both energetically favourable and feasible, allows one to reconcile the a priori dissimilar experimental results, plus points for a bandgap reduction in solar light triggered processes in situations with low $\mathrm{W}$ content.

\section{Acknowledgements}

This research was supported by the Spanish MINECO/FEDER CTQ2015-64618-R grant and, in part, by Generalitat de Catalunya (grants 2017SGR13 and XRQTC) and by the NOMAD Center of Excellence project, which received funding from the European Union's Horizon 2020 research and innovation programme under grant agreement No 676580. F.V. thanks MINECO for a postdoctoral Ramón y Cajal (RyC) research contract (RYC-2012-10129) and F.I. acknowledges additional support from the 2015 ICREA Academia Award for Excellence in University Research. 
Table 1 Employed supercell dimensions, alongside with the used k-points meshes, and the concentration (Conc.) of defects or dopants inside.

\begin{tabular}{lll}
\hline Supercell & k-points & Conc. \\
\hline \hline$(1 \times 1 \times 1)$ & $17 \times 17 \times 17$ & $50.00 \%$ \\
$(1 \times 1 \times 2)$ & $17 \times 17 \times 9$ & $25.00 \%$ \\
$(2 \times 1 \times 1)$ & $9 \times 17 \times 17$ & $25.00 \%$ \\
$(2 \times 2 \times 1)$ & $9 \times 9 \times 17$ & $12.50 \%$ \\
$(2 \times 1 \times 2)$ & $9 \times 17 \times 9$ & $12.50 \%$ \\
$(2 \times 2 \times 2)$ & $9 \times 9 \times 9$ & $6.25 \%$ \\
$(3 \times 3 \times 3)$ & $5 \times 5 \times 5$ & $1.85 \%$ \\
\hline
\end{tabular}


Table 2 Formation energies, $E_{f}$, in $\mathrm{eV}$, for different native point defects $\left(\mathrm{V}_{\mathrm{Zn}}\right.$ and $\left.\mathrm{V}_{\mathrm{O}}\right)$ and $\mathrm{W}$ doping sites $\left(\mathrm{W}_{\mathrm{Zn}}, \mathrm{W}_{\mathrm{i}}\right.$, and $\left.\mathrm{W}_{\mathrm{O}}\right)$, at different concentrations.

\begin{tabular}{cccccc}
\hline at. \% & $\mathrm{V}_{\mathrm{Zn}}$ & $\mathrm{V}_{\mathrm{O}}$ & $\mathrm{W}_{\mathrm{Zn}}$ & $\mathrm{W}_{\mathrm{i}}$ & $\mathrm{W}_{\mathrm{O}}$ \\
\hline 50 & 6.50 & 6.43 & -6.03 & -7.43 & -0.40 \\
25 & 5.54 & 6.46 & -5.54 & -7.04 & 0.23 \\
12.5 & 6.36 & 6.63 & -3.54 & -4.75 & 1.98 \\
6.25 & 6.40 & 6.52 & -3.66 & -3.43 & 4.76 \\
1.85 & 6.43 & 6.25 & -5.17 & -2.93 & 4.70 \\
\hline
\end{tabular}


Table 3 Wurtzite $c$ lattice expansion/contraction, $\Delta c$, in $\%$, for different native point defects $\left(\mathrm{V}_{\mathrm{Zn}}\right.$ and $\left.\mathrm{V}_{\mathrm{O}}\right)$ and $\mathrm{W}$-doping positions $\left(\mathrm{W}_{\mathrm{Zn}}, \mathrm{W}_{\mathrm{i}}\right.$, and $\left.\mathrm{W}_{\mathrm{O}}\right)$, at different concentrations.

\begin{tabular}{cccccc}
\hline at. \% & $\mathrm{V}_{\mathrm{Zn}}$ & $\mathrm{V}_{\mathrm{O}}$ & $\mathrm{W}_{\mathrm{Zn}}$ & $\mathrm{W}_{\mathrm{i}}$ & $\mathrm{W}_{\mathrm{O}}$ \\
\hline 50 & -26.25 & -8.48 & 18.92 & 54.79 & 46.08 \\
25 & -6.31 & -3.66 & 11.06 & 28.01 & 24.85 \\
12.5 & 0.36 & -3.31 & 9.88 & 18.42 & 16.15 \\
6.25 & -0.11 & -1.76 & 0.27 & 15.31 & 7.71 \\
1.85 & -0.10 & -1.10 & -0.59 & 1.14 & 1.21 \\
\hline
\end{tabular}


Table 4 Wurtzite $\mathrm{ZnO}$ magnetic moment, $\mu$, in $\mu_{\mathrm{B}}$, for different native point defects $\left(\mathrm{V}_{\mathrm{Zn}}\right.$ and $\mathrm{V}_{\mathrm{O}}$ ) and $\mathrm{W}$-doping positions $\left(\mathrm{W}_{\mathrm{Zn}}, \mathrm{W}_{\mathrm{i}}\right.$, and $\left.\mathrm{W}_{\mathrm{O}}\right)$, at different concentrations.

\begin{tabular}{cccccc}
\hline at. \% & $\mathrm{V}_{\mathrm{Zn}}$ & $\mathrm{V}_{\mathrm{O}}$ & $\mathrm{W}_{\mathrm{Zn}}$ & $\mathrm{W}_{\mathrm{i}}$ & $\mathrm{W}_{\mathrm{O}}$ \\
\hline 50 & 1.88 & 0.00 & 0.00 & 0.00 & 0.00 \\
25 & 0.00 & 0.00 & 0.00 & 0.00 & 0.00 \\
12.5 & 2.00 & 0.00 & 0.00 & 0.00 & 0.00 \\
6.25 & 1.80 & 0.00 & 2.01 & 0.00 & 0.02 \\
1.85 & 1.57 & 0.00 & 1.99 & 2.03 & 0.30 \\
\hline
\end{tabular}


Fig. 1 Formation energies, $E_{f}$, in $\mathrm{eV}$, for native defects of $\mathrm{ZnO} \mathrm{V}_{\mathrm{O}}$ and $\mathrm{V}_{\mathrm{Zn}}$, and $\mathrm{W}_{\mathrm{O}}, \mathrm{W}_{\mathrm{Zn}}$, and $\mathrm{W}_{\mathrm{i}}$ doping situations as a function of defect/dopant concentration.

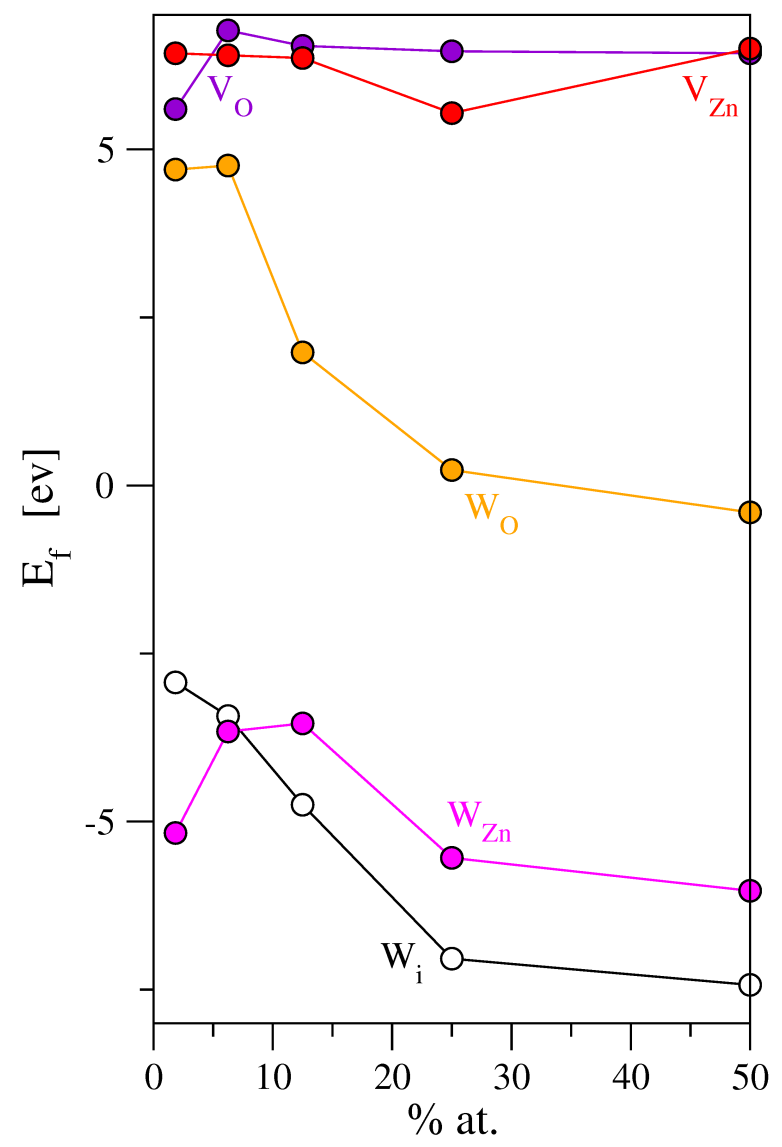


Fig. 2 Wurtzite $c$ lattice expansion/contraction, $\Delta c$, in $\%$, for $\mathrm{V}_{\mathrm{O}}$ and $\mathrm{V}_{\mathrm{Zn}}$ point defects and $\mathrm{W}_{\mathrm{O}}, \mathrm{W}_{\mathrm{Zn}}$, and $\mathrm{W}_{\mathrm{i}}$ doping situations as a function of defect/dopant concentration.

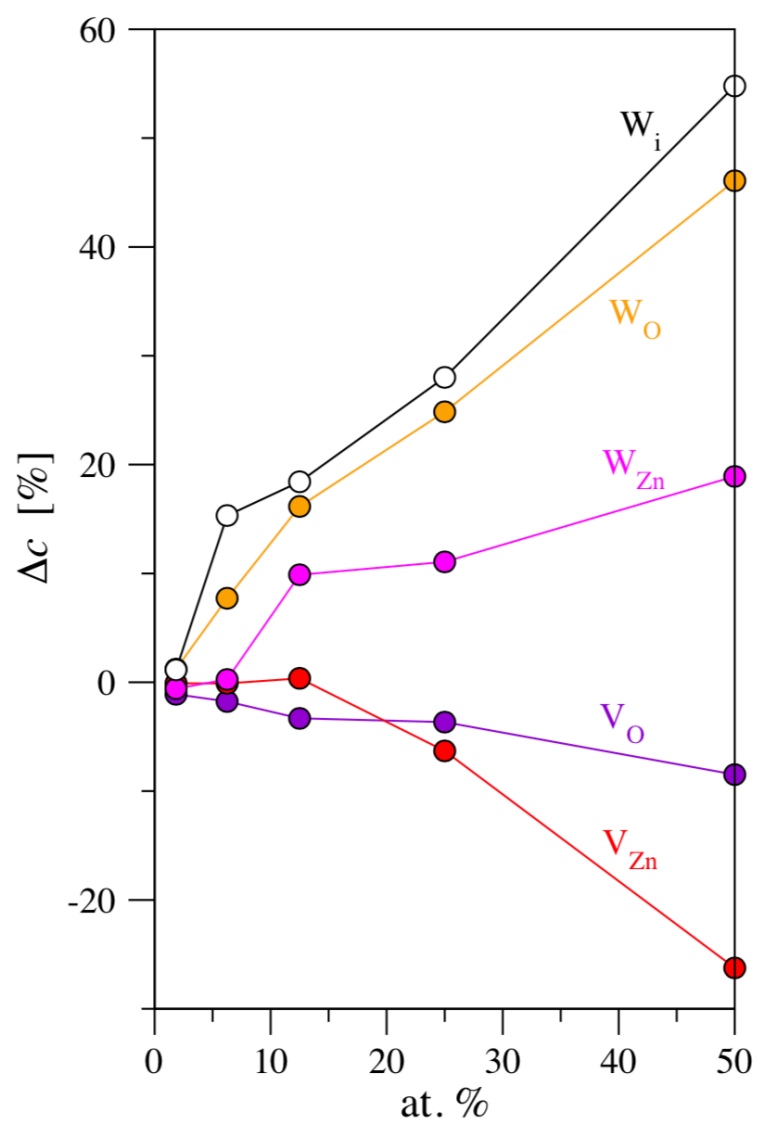


Fig. 3 Wurtzite magnetic moment ( $\mu$ in Bohr magnetons, $\mu_{B}$ ) for $V_{O}$ and $V_{Z n}$ point defects and $\mathrm{W}_{\mathrm{O}}, \mathrm{W}_{\mathrm{Zn}}$, and $\mathrm{W}_{\mathrm{i}}$ doping situations as a function of defect/dopant concentrations.

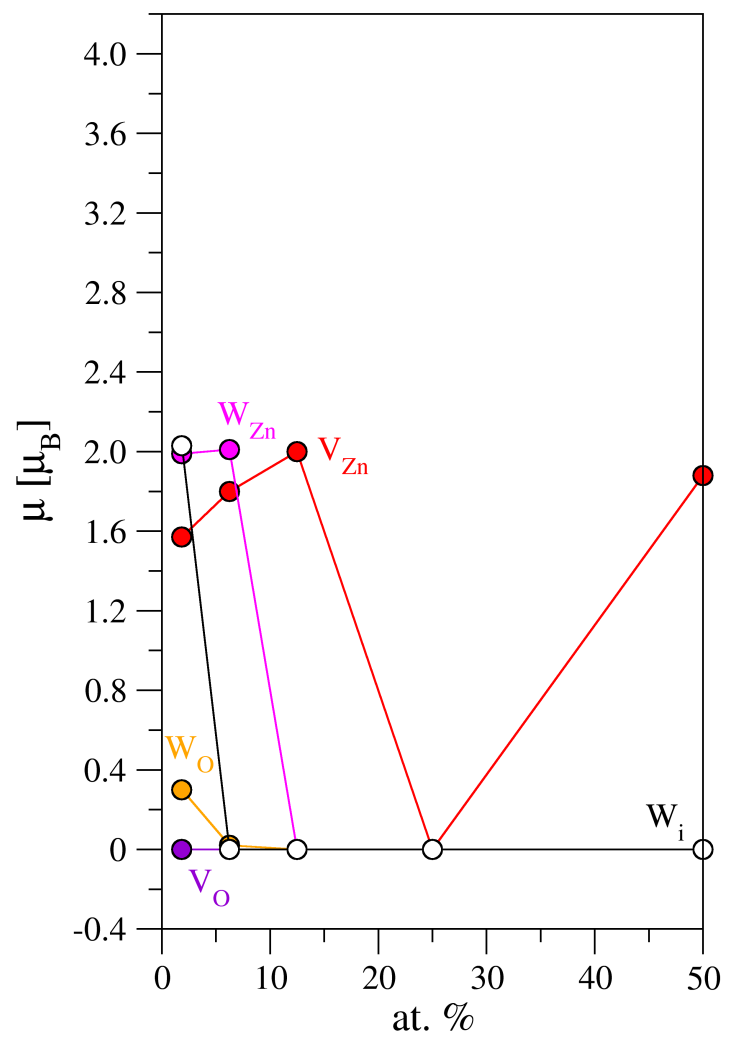


Fig. 4 Projected density of states (DOS) of $\mathrm{W}_{\mathrm{Zn}}+\mathrm{V}_{\mathrm{Zn}}$ (top panel) and $\mathrm{W}_{\mathrm{Zn}}+2 \cdot \mathrm{V}_{\mathrm{Zn}}$ (bottom panel) situations, colour coded, as well as band and energy gaps, as obtained at PBE level. Values are obtained of a situations represented in a $(2 \times 2 \times 2)$ supercell, and values are given in $\mathrm{eV}$.

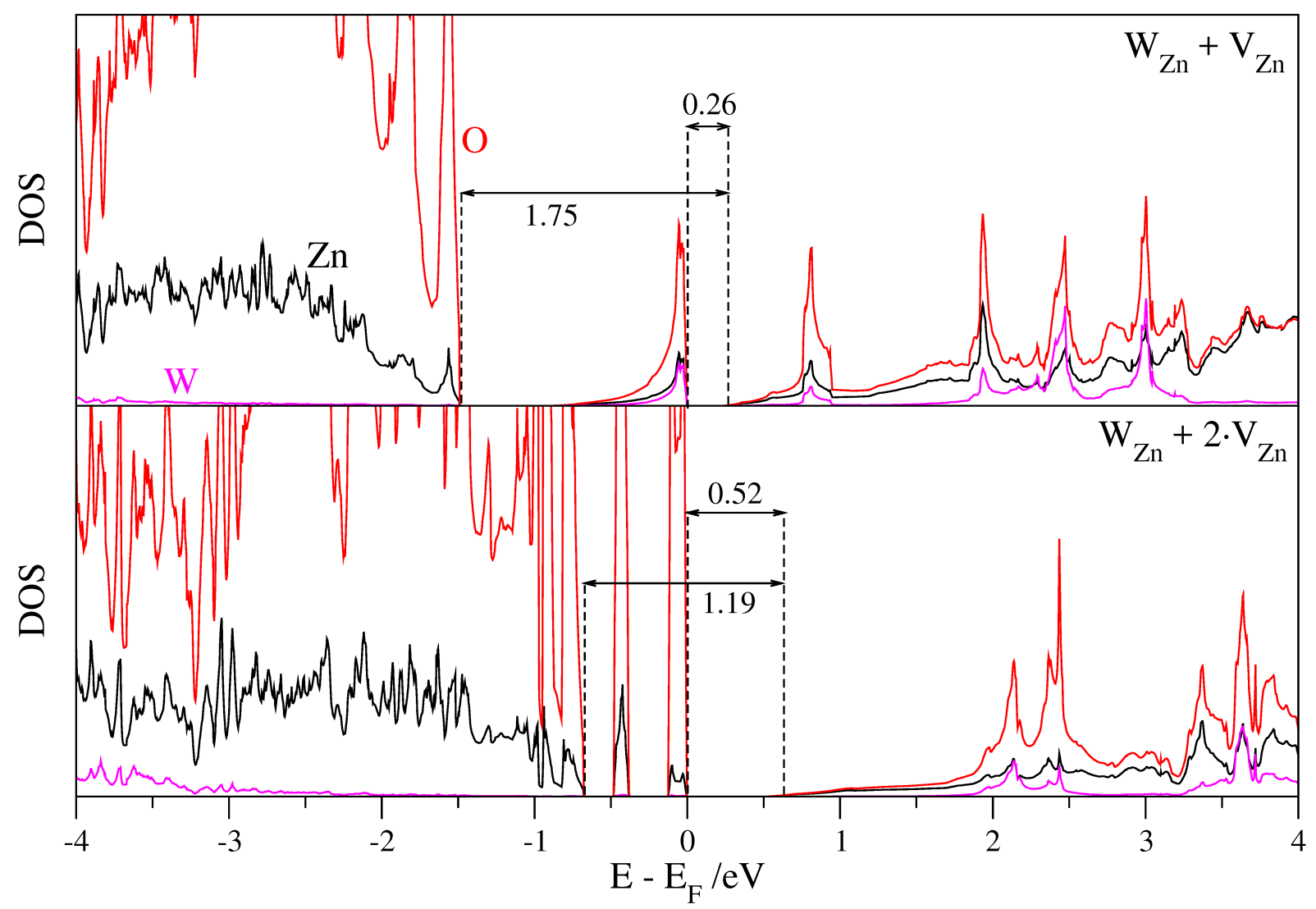


Fig. 5 Local view of the $\mathrm{W}_{\mathrm{Zn}}+2 \mathrm{~V}_{\mathrm{Zn}}$ cluster in the $(2 \times 2 \times 2)$ supercell, showing the distorted tetrahedral environment of W. Atoms are represented by coloured spheres.

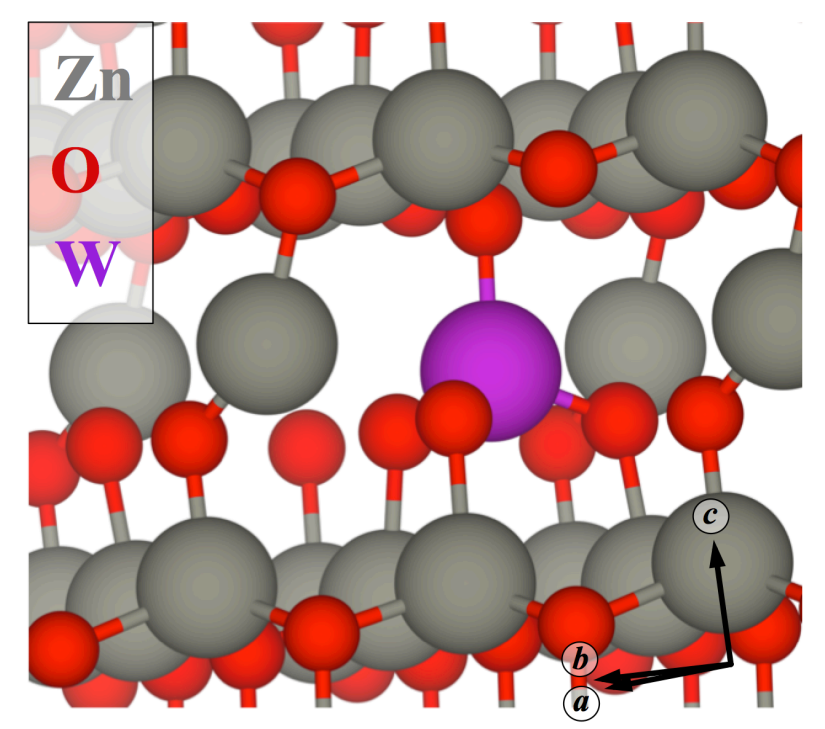


Fig. 6 Projected density of states (DOS) of $\mathrm{W}_{\mathrm{Zn}}+\mathrm{V}_{\mathrm{Zn}}$ (top panel) and $\mathrm{W}_{\mathrm{Zn}}+2 \cdot \mathrm{V}_{\mathrm{Zn}}$ (bottom panel) situations, colour coded, as well as band and energy gaps, as obtained at PBE+U level. Values are obtained of a situations represented in a $(2 \times 2 \times 2)$ supercell, and values are given in $\mathrm{eV}$.

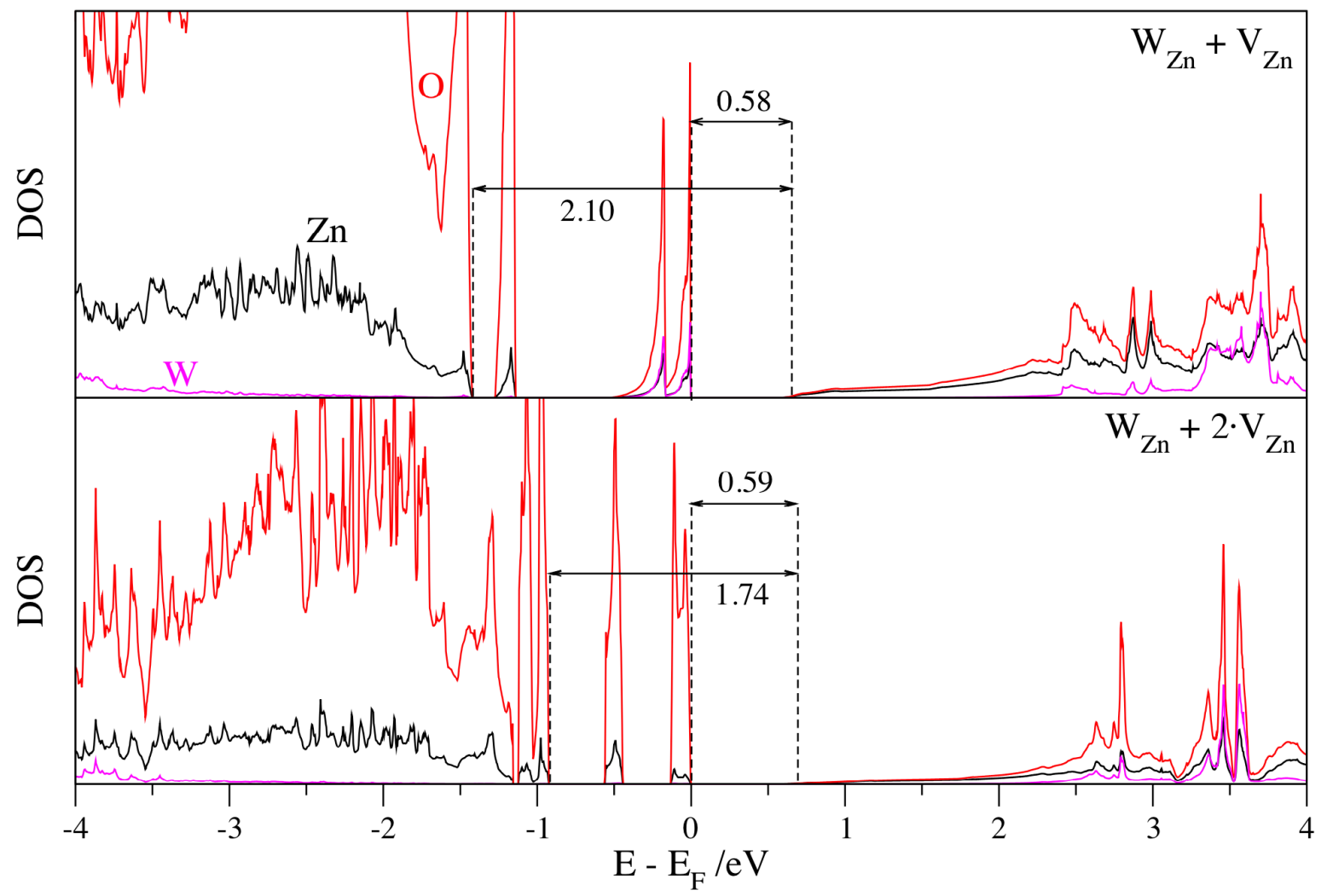


Table of Contents

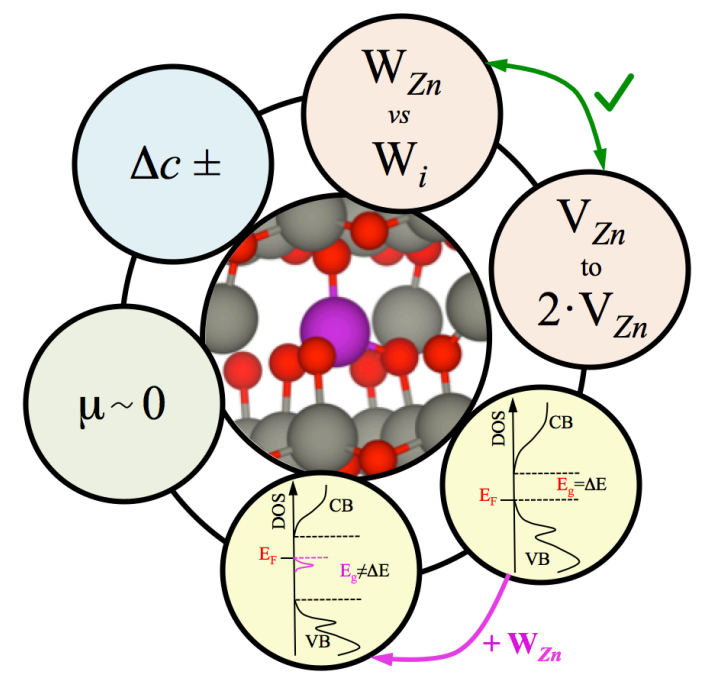




\section{References}

(1) Mang, A.; Reimann, K.; Rübenacke, S.; Band Gaps, Crystal-Field Splitting, Spin-Orbit Coupling, and Exciton Binding Energies in $\mathrm{ZnO}$ under Hydrostatic Pressure. Solid State Commun. 1995, 94, 251-254.

(2) Reynolds, D. C.; Look, D. C.; Jogai, B.; Litton, C. W.; Cantwell, G.; Harsch, W. C.; Valence-Band Ordering in ZnO. Phys. Rev. B 1999, 60, 2340-2344.

(3) Djurisic, A. B.; Leung, Y. H.; Optical Properties of ZnO Nanostructures. Small 2006, 2, 944-961.

(4) Van de Walle, C. G.; Janotti, A.; Fundamentals of Zinc Oxide as a Semiconductor. Rep. Prog. Phys. 2009, 72, 126501.

(5) Goldberger, J.; Sirbuly, D. J.; Law, M.; Yang, P.; ZnO Nanowire Transistors. J. Phys. Chem. B 2005, 109, 9-14.

(6) Kind, H.; Yan, H. Q.; Messer, B.; Law, M.; Yang, P. D.; Nanowire Ultraviolet Photodetectors and Optical Switches. Adv. Mater. 2002, 14, 158.

(7) Bagnall, D. M.; Chen, Y. F.; Zhu, Z.; Yao, T.; Koyama, S.; Shen, M. Y.; Goto, T.; Optically Pumped Lasing of $\mathrm{ZnO}$ at Room Temperature. Appl. Phys. Lett. 1997, 70, 2230-2232.

(8) Colvin, V. L.; Schlamp, M. C.; Alivisatos, A. P.; Light-Emitting Diodes Made from Cadmium Selenide Nanocrystals and a Semiconducting Polymer. Nature 1994, 370, 354-357.

(9) Huang, M. H.; Mao, S.; Feick, H.; Yan, H. Q.; Wu, Y. Y.; Kind, H.; Weber, E.; Russo, R.; Yang P. D.; Room-Temperature Ultraviolet Nanowire Nanolasers. Science 2001, 292, 1897-1899.

(10) Wang, Z. L.; Song, J. H.; Piezoelectric Nanogenerators Based on Zinc Oxide Nanowire Arrays. Science 2006, 312, 242-246.

(11) Duran, P.; Capel, F.; Tartaj, J.; Moure, C.; A Strategic Two-Stage Low-Temperature Thermal Processing Leading to Fully Dense and Fine-Grained Doped-ZnO Varistors. Adv. Mater. 2002, 14, 137-141.

(12) Gnichwitz, J. F.; Marczak, R.; Werner, F.; Lang, N. N; Jux, N.; Guldi, D. M.; Peukert, W.; Hirsch, A.; Efficient Synthetic Access to Cationic Dendrons and Their Application for $\mathrm{ZnO}$ Nanoparticles Surface Functionalization: New Building Blocks for DyeSensitized Solar Cells. J. Am. Chem. Soc. 2010, 132, 17910-17920. 
(13) Marczak, R.; Werner, F.; Ahmad, R.; Lobaz, V.; Guldi, D. M.; Peukert, W.; Detailed Investigations of $\mathrm{ZnO}$ Photoelectrodes Preparation for Dye Sensitized Solar Cells. Langmuir 2011, 27, 3920-3929.

(14) O’Regan, B.; Grätzel, M.; A Low-Cost, High-Efficiency Solar Cell Based on DyeSensitized Colloidal $\mathrm{TiO}_{2}$ Films. Nature 1991, 353, 737-739.

(15) Granqvist, C. G.; Electrochromic Tungsten Oxide Films: Review of Progress 19931998. Sol. Energy Mater. Sol. Cells 2000, 60, 201.

(16) Bamwenda, R. G.; Sayama, K.; Arakawa, H.; The Effect of Selected Reaction Parameters on the Photoproduction of Oxygen and Hydrogen from a $\mathrm{WO}_{3}-\mathrm{Fe}^{2+}-\mathrm{Fe}^{3+}$ Aqueous Suspension. J. Photochem. Photobiol. A 1999, 122, 175.

(17) Sato, T.; Suzuki, H.; Kido, O.; Kurumada, M.; Kamitsuji, K.; Kimura, Y.; Takeda, A.; Kaneko, S.; Saito, Y.; Kaito, C.; Novel Method of Doping Tungsten into Zinc Oxide Ultrafine Particle Using RF Plasma System. J. Crystal Growth 2004, 265, 149-153.

(18) Moafi, H. F.; Zanjanchi, M. A.; Shojaie, A. F.; Tungsten-Doped ZnO Nanocomposite: Synthesis, Characterization, and Highly Active Photocatalyst Toward Dye Photodegradation. Mat. Chem. Phys. 2013, 139, 856-864.

(19) Shirini, F.; Abedini, M.; Zamani, S.; Moafi, H. F.; Introduction of W-doped ZnO Nanocomposite as a New and Efficient Nanocatalyst for the Synthesis of Biscoumarins in Water. J. Nanostruct. Chem. 2015, 5, 123-130.

(20) Can, M. M.; Firat, T.; Shah, S. I.; Magnetoelectrical Properties of W Doped ZnO Thin Films. J. Magn. Magn. Mater. 2012, 324, 4054-4060.

(21) Ngom, B. D.; Chaker, M.; Manyala, N.; Lo, B.; Maaza, M.; Beye, A. C.; TemperatureDependent Growth Mode of W-doped ZnO Nanostructures. Appl. Surf. Sci. 2011, 257, 6226-6232.

(22) Ngom, B. D.; Sakho, O.; Manyala, N.; Kana, J. B.; Mlungisi, N.; Guerbous, L.; Fasasi, A. Y.; Maaza, M.; Beye, A. C.; Structural, Morphological and Photoluminescence Properties of W-Doped ZnO Nanostructures. Appl. Surf. Sci. 2009, 255, 7314-7318.

(23) Zhang, C.; Chen, X.-L.; Geng, X.-H.; Tian, C.-S.; Huang, Q.; Zhao, Y.; Zhang, X.-D.; Temperature-Dependent Growth and Properties of W-Doped ZnO Thin Films Deposited by Reactive Magnetron Sputtering. Appl. Surf. Sci. 2013, 274, 371-377.

(24) Suzuki, T. T.; Adachi, Y.; Saito, N.; Hashiguchi, M.; Sakaguchi, I.; Ohashi, N.; Hishita, S.; Surface Segregation of W Doped in ZnO Thin Films. Surf. Sci. 2014, 625, 1-6. 
(25) Shannon, R. D.; Revised Effective Ionic Radii and Systematic Studies of Interatomic Distances in Halides and Chalcogenides. Acta Crystallogr., Sect. A: Cryst. Phys., Diffr., Theor. Gen. Crystallogr., 1976, 32, 751-767.

(26) Adachi, Y.; Saito, N.; Hashiguchi, M.; Sakaguchi, I.; Suzuki, T.; Ohashi, N.; Hishita, S.; Electrical and Optical properties of W-Doped ZnO Films Grown on (112̄0) Sapphire Substrates Using Pulsed Laser Deposition. J. Ceram. Soc. Jpn. 2014, 122, 908-913.

(27) Kohan, A. F.; Ceder, G.; Morgan, D.; Van de Walle, C. G.; First-Principles Study of Native Point Defects in ZnO. Phys. Rev. B 2000, 61, 15019-15027.

(28) Tesfamichael, T.; Cetin, C.; Piloto, C.; Arita, M.; Bell, J.; The Effect of Pressure and W-Doping on the Properties of $\mathrm{ZnO}$ Thin Films for $\mathrm{NO}_{2}$ Gas Sensing. Appl. Surf. Sci. 2015, 357, 728-734.

(29) Chu, J.; Peng, X. Y.; Dasari, K.; Palai, R.; Feng, P.; The Shift of Optical Band Gap in W-Doped ZnO with Oxygen Pressure and Doping Level. Mater. Res. Bull. 2014, 54, 73-77.

(30) Yan-Feng, W.; Qian, H.; Qing-Gong, S.; Yang, L.; Chang-Chun, W.; Ying, Z.; XiaoDan, Z.; Theoretical and Experimental Investigation of W Doped ZnO. Acta Phys. Sin. 2012, 61, 137801.

(31) Li, Y.; Hou, Q.; Zhao, C.; Xu, Z.; Study on Electrical Structure and Magneto-Optical Properties of W-Doped ZnO. J. Magn. Magn. Mater. 2018, 451, 697-703.

(32) Ren, J.; Zhang, H.; Cheng, X.; Electronic and Magnetic Properties of All $3 d$ Transition-Metal-Doped ZnO Monolayers. Int. J. Quantum Chem. 2013, 113, 22432250.

(33) Shi, S.; Gao, J.; Liu, Y.; Zhao, Y.; Wu, Q.; Ju, W.; Ouyang, C.; Xiao, R. Multi-scale Computation Methods: Their Applications in Lithium-ion Battery Research and Development. Chin. Phys. B 25, 1, 018212.

(34) Perdew, J. P.; Burke, K.; Ernzerhof, M.; Generalized Gradient Approximation Made Simple. Phys. Rev. Lett. 1996, 77, 3865-3868.

(35) Viñes, F.; Lamiel-Garcia, O.; Illas, F.; Bromley, S. T.; Size Dependent Structural and Polymorphic Transitions in ZnO: From Nanocluster to Bulk. Nanoscale 2017, 9, 1006710074.

(36) Sousa, C.; Tosoni, S.; Illas, F.; Theoretical Approaches to Excited-State-Related Phenomena in Oxide Surfaces. Chem. Rev. 2013, 113, 4456-4495. 
(37) Viñes, F.; Illas, F.; Electronic Structure of Stoichiometric and Reduced ZnO from Periodic Relativistic All Electron Hybrid Density Functional Calculations Using Numeric Atom-Centered Orbitals. J. Comput. Chem. 2017, 38, 523-529.

(38) Demiroglu, I.; Tosoni, S.; Illas, F.; Bromley, S. T.; Bandgap Engineering through Nanoporosity. Nanoscale 2014, 6, 1181.

(39) Morales García, A.; Valero, R.; Illas, F.; An Empirical, yet Practical Way To Predict the Band Gap in Solids by Using Density Functional Band Structure Calculations. J. Phys. Chem. C 2017, 121, 18862-18866.

(40) Dudarev, S. L.; Botton, G. A.; Savrasov, S. Y.; Humphreys, C. J.; Sutton, A. P. Electron-energy-loss Spectra and the Structural Stability of Nickel Oxide: An LSDA+U Study. Phys. Rev. B 1998, 57, 1505.

(41) Kresse, G.; Furthmüller, J.; Efficient Iterative Schemes for Ab Initio Total-Energy Calculations Using a Plane-Wave Basis Set. Phys. Rev. B 1996, 54, 11169-11186.

(42) Viñes, F.; Iglesias-Juez, A.; Fernández-Garcia, M.; Illas, F.; Hydroxyl Identification on $\mathrm{ZnO}$ by Infrared Spectroscopies: Theory and Experiments. J. Phys. Chem. C 2014, 118 , 1492-1505.

(43) Iglesias-Juez, A.; Viñes, F.; Lamiel-Garcia, O.; Fernández-Garcia, M.; Illas, F.; Morphology Effects in Photoactive $\mathrm{ZnO}$ Nanostructures: Photooxidative Activity of Polar Surfaces. J. Mater. Chem. A 2015, 3, 8782-8792.

(44) Blöchl, P. E.; Projector Augmented-Wave Method. Phys. Rev. B 1994, 50, 17953 17979.

(45) Monkhorst, H. J.; Pack, J. D.; Special Points for Brillouin-Zone Integrations. Phys. Rev. $B$ 1976, 13, 5188-5192.

(46) Janotti, A.; Van de Walle, C. G.; Native Point Defects in ZnO. Phys. Rev. B 2007, 76, 165202.

(47) Bader, R. F. W. Atoms in Molecules. In Encyclopedia of Computational Chemistry; John Wiley \& Sons, Ltd: Chichester, UK, 2002.

(48) Moreira, I. de P.R.; Illas, F.; Martin, R. L.; Effect of Fock Exchange on the Electronic Structure and Magnetic Coupling in NiO. Phys. Rev. B 2002, 65, 155102.

(49) Walsh, A.; Sokol, A. A.; Buckeridge, J.; Scanlon, D. O.; Catlow, C. R. A. Electron Counting in Solids: Oxidation States, Partial Charges, and Ionicity. J. Phys. Chem. Lett. 2017, 8, 2074-2075. 
(50) Ngom, B. D.; Sakho, O.; Ndiaye, S.; Bartali, R.; Diallo, A.; Gaye, M. B.; Bady, S.; Manyala, N.; Maaza, M.; Beye, A. C.; Photon-Induced Tunable and Reversible Wettability of Pulsed Laser Deposited W-Doped ZnO Nanorods. Eur. Phys. J. Appl. Phys. 2011, 55, 20501. 